\title{
To study 3 R's (Reuse, reduce and recycling) pattern of household waste
}

Surabhi Bharti and Aditi Vats

Received: 04.12.2017; Revised: 20.03.2018; Accepted: 07.04.2018

See end of the paper for authors' affiliations

Surabhi Bharti

Department of Family Resource

Management, College of Home

Science, G.B. Pant University of

Agriculture and Technology,

Pantnagar, U.S. Nagar

(Uttarakhand) India
ABSTRACT : Household waste refers to waste material usually generated in the residential environment. Indiscriminate dumping, irregular collection, poor storage and inadequate resources are the main problems associated with improper handling of household waste. This leads to various health related problems like cholera, dysentery, typhoid etc. and also have a negative impact on the environment by polluting land, air and water. So there is a need to manage the domestic household waste in such a way that it in will lead to a safe and healthy environment. A descriptive research design was chosen for the study. A pre-coded interview schedule, knowledge and awareness scales was used to gather the required information. The collected data was tabulated and analyzed with the help of descriptive and statistical analysis.

KEY WORDS: Waste disposed, Solid waste management

- HOW TO CITE THIS PAPER : Bharti, Surabhi and Vats, Aditi (2018). To study 3 R's (Reuse, reduce and recycling) pattern of household waste . Asian J. Home Sci., 13 (1) : 86-89, DOI: 10.15740/HAS/AJHS/ 13.1/86-89. Copyright@ 2018: Hind Agri-Horticultural Society. 